\title{
Correction to: Embodying Middle Class Gender Aspirations
}

\section{Correction to:}

K. Xie, Embodying Middle Class Gender Aspirations, Gender, Sexualities and Culture in Asia, https://doi.org/10.1007/978-981-16-1139-1

The original version of this book was updated with the following additional corrections in the text post publication: (1) In Chapter 1, Figures 1.3 and 1.4 have been removed. (2) In Chapter 3, article note has been newly added. (3) In Chapter 4, figure captions were updated. (4) Cover credit text has been newly added in Frontmatter. The book has been updated with the changes.

The updated version of this book can be found at https://doi.org/10.1007/978-981-16-1139-1_1 https://doi.org/10.1007/978-981-16-1139-1_3 https://doi.org/10.1007/978-981-16-1139-1_4 https://doi.org/10.1007/978-981-16-1139-1

(C) The Author(s), under exclusive license to Springer Nature Singapore Pte Ltd. 2021

K. Xie, Embodying Middle Class Gender Aspirations, Gender, Sexualities and Culture in Asia, https://doi.org/10.1007/978-981-16-1139-1_8 